\title{
Peripheral perfusion index predicting prolonged ICU stay earlier and better than lactate in surgical patients: an observational study
}

Xinge Shi, Ming Xu, Xu Yu and Yibin Lu*

\begin{abstract}
Background: Peripheral perfusion index (PPI) is an indicator reflecting perfusion. Patients undergoing long time surgeries are more prone to hypoperfusion and increased lactate. Few studies focusing on investigating the association between PPI and surgical patients' prognoses. We performed this study to find it out.

Methods: From January 2019 to September 2019, we retrospected all surgical patients who were transferred to $I C U$, Xinyang Central hospital, Henan province, China. Inclusive criteria: age $\geq 18$ years old; surgical length $\geq 120$ min. Exclusive criteria: died in ICU; discharging against medical advice; existing diseases affecting blood flow of upper limbs, for example, vascular thrombus in arms; severe liver dysfunction.

We defined "prolonged ICU stay" as patients with their length of ICU stay longer than $48 \mathrm{~h}$. According to the definition, patients were divided into two groups: "prolonged group" (PG) and "non-prolong group" (nPG). Baseline characteristics, surgical and therapeutic information, ICU LOS, SOFA and APACHE II were collected. Besides we gathered data of following parameters at 3 time points (TO: ICU admission; T1: $6 \mathrm{~h}$ after admission; T2: $12 \mathrm{~h}$ after admission): mean artery pressure (MAP), lactate, heart rate (HR), PPI and body temperature. Data were compared between the 2 groups. Multivariable binary logistic regression and ROC (receiver operating characteristic) curves were performed to find the association between perfusion indictors and ICU LOS.

Results: Eventually, 168 patients were included, 65 in PG and 103 in nPG. Compared to nPG, patients in PG had higher blood lactate and lower PPI. PPI showed significant difference between two groups earlier than lactate ( $T_{0}$ vs $\left.T_{1}\right)$. The value of PPI at two time points was lower in PG than $\mathrm{nPG}(\mathrm{TO}: 1.09 \pm 0.33$ vs $1.41 \pm 0.45, p=0.001$; T1: $1.08 \pm 0.37$ vs $1.49 \pm 0.41, p<0.001)$.

Increased lactate $\mathrm{T}_{1}(\mathrm{OR} 3.216 ; 95 \% \mathrm{Cl} 1.253-8.254, P=0.015)$ and decreased $\mathrm{PPI}_{\mathrm{T} 1}(\mathrm{OR} 0.070 ; 95 \% \mathrm{Cl} 0.016-0.307$, $P<0.001$ ) were independently associated with prolonged ICU stay. The area under ROC of the $\mathrm{PPI}_{\mathrm{T} 1}$ for predicting ICU stay $>48 \mathrm{~h}$ was 0.772 , and the cutoff value for $\mathrm{PPI}_{\mathrm{T} 1}$ was 1.35 , with $83.3 \%$ sensitivity and $73.8 \%$ specificity.
\end{abstract}

Conclusions: PPI and blood lactate at $\mathrm{T}_{1}(6 \mathrm{~h}$ after ICU admission) are associated with ICU LOS in surgical patient. Compared to lactate, PPI indicates hypoperfusion earlier and more accurate in predicting prolonged ICU stay.

Keywords: Peripheral perfusion index, Surgical patients, Critical patients, Hypoperfusion, Lactate, Length of ICU stay

\footnotetext{
* Correspondence: Iyb_sxgicu@163.com

Department of Critical Care Medicine, Xinyang Central Hospital, No.1, Siyi

Road, Xinyang 464000, Henan Province, China
}

(c) The Author(s). 2020 Open Access This article is licensed under a Creative Commons Attribution 4.0 International License, which permits use, sharing, adaptation, distribution and reproduction in any medium or format, as long as you give appropriate credit to the original author(s) and the source, provide a link to the Creative Commons licence, and indicate if changes were made. The images or other third party material in this article are included in the article's Creative Commons licence, unless indicated otherwise in a credit line to the material. If material is not included in the article's Creative Commons licence and your intended use is not permitted by statutory regulation or exceeds the permitted use, you will need to obtain permission directly from the copyright holder. To view a copy of this licence, visit http://creativecommons.org/licenses/by/4.0/. The Creative Commons Public Domain Dedication waiver (http://creativecommons.org/publicdomain/zero/1.0/) applies to the data made available in this article, unless otherwise stated in a credit line to the data. 


\section{Introduction}

Hemodynamic changes in postoperative patients are complex and various. Many patients would manifest increased level of blood lactate after long-term surgeries [1-3]. Ensuring adequate perfusion is essential for recovery and better prognosis.

Many indicators have been proved reliable in reflecting perfusion. Among them, blood lactate is one of the widest used indexes guiding fluid management and resuscitation $[4,5]$. But it still has some drawbacks. The most evident one is lactate is delayed in reflecting real-time perfusion. As we all know, from the beginning of hypoperfusion to elevated lactate, there is a time interval. If we use lactate as an indicator of hypoperfusion, we will take measures later than the real start of inadequate perfusion, which is why we turn to a more timely parameter: peripheral perfusion index (PPI).

Some researchers have proved PPI is a reflector of hypoperfusion [6,7] and is associated with patients' mortality [8]. But most of these studies are about septic shock. Apart from that, no study has been about comparing lactate with PPI, trying to figure out which one is superior in predicting patients' outcomes.

If we can prove PPI is comparable or superior to lactate in reflecting postoperative patients' prognoses, we will take beneficial interventions earlier because PPI is more instant than lactate in mirroring perfusion state. That is why we performed this study to investigate the role of PPI in predicting postoperative patients' prognoses and to compare PPI with lactate, finding out their strengths and limitations.

\section{Patients and methods}

\section{Patients}

The Institutional Research and Ethics Committee of the Xinyang Central Hospital approved this study. Written informed consent was waived since it was a retrospective study.

This was a retrospective study of all surgical patients who were admitted to ICU in Xinyang Central Hospital (Henan province, China) from January 1st, 2019 to September 30th, 2019. The inclusive criteria are following:1) age $\geq 18$ years old; 2) surgical length $\geq 120 \mathrm{~min}$. Exclusive criteria: 1) died in ICU; 2) discharging against medical advice; 3) existing diseases affecting peripheral blood flow, for example, vascular thrombus in arms; 4) severe liver dysfunction.

Prolonged ICU stay was defined as ICU LOS longer than $48 \mathrm{~h}$ (from the time of arrival in ICU). Patients were divided into two groups according to the definition: "prolong group" (PG) and "non-prolong group" (nPG).

\section{Data collection}

Before we commenced data collection, we had estimated the minimum sample size we needed to obtain (supplement.1). The electronic medical records and anaesthesia charts of all recruited patients were reviewed to collect the following information: gender, age, comorbidities(CAD: coronary artery disease; COPD: chronic obstructive pulmonary disease; CKD: chronic kidney disease; HTN: hypertension; PMI: pacemaker implantation), surgical types and length, volume of intraoperative fluid infusion, fluid balance of 0-6 h and 0-12 h in ICU, the application of vasoactive agent in the first $12 \mathrm{~h}$ in ICU, SOFA(Sequential Organ Failure Assessment), APACHE II(Acute Physiology and Chronic Health Evaluation) on 1st day in ICU and the length of ICU stay.

We also collected each patient's perfusion associated parameters at three different time points: ICU admission(T0), $6 \mathrm{~h}$ after ICU admission(T1), $12 \mathrm{~h}$ after ICU admission(T2). The perfusion related variables include mean artery pressure (MAP), heart rate (HR), peripheral perfusion index (PPI) and body temperature (axillary). MAP, HR and PPI would be obtained by monitors continuously (Philips IntelliVue MP50; Koninklijke Philips, The Netherlands) and exported to our medical records database automatically. PPI was captured by the pulse oximeter and blood pressure was measured using the oscillometric non-invasive technique or via radial arterial cannulation using pulse contour analysis.

As for PPI, we used its absolute value in every $15 \mathrm{~min}$ to calculate the averaged value for each hour. All PPIs were averaged values (in the first, sixth and twelfth hour in ICU).

\section{Statistical analysis}

This is a retrospective study only involving in-hospital information. We assumed missing data were limited to a small number of observations and adopted likewise deletion to handle missing data.

Descriptive analyses were performed for the nPG and PG groups. Continuous variables are expressed as means \pm standard deviations, and categorical variables are expressed as absolute values and percentages. For the continuous variables, the data were analyzed using Student's t-test, the Mann-Whitney $U$ test or the Kruskal-Wallis test depending on the data distribution and the number of variables. The categorical variables were analyzed using chi-square or Fisher's exact tests.

Before we performed the multivariate logistic regression analysis, univariate analysis was performed for each potential risk factor of prolonged ICU stay. We defined $P<0.05$ in univariate analyzation as the threshold of a variable qualified to be included in multivariate logistic regression model. As for indicators associated with prolonged ICU stay, the receiver operating characteristic (ROC) analyses were performed to test each indicator's efficacy in predicting prolong ICU stay. All comparisons were two-tailed, and $P<0.05$ was required to exclude 
the null hypothesis. The statistical analysis was performed using IBM SPSS Statistics, Version 20.0 (Armonk, NY: IBM Corp).

\section{Results}

From January to September 2019, a total of 252 surgical patients were transferred to ICU, Xinyang Central Hospital, Henan Province, China. 84 patients were excluded for several reasons and 169 patients were recruited finally. They were divided into 2 groups according to their ICU LOS: 65 patients in "prolonged group", 103 patients in "non-prolonged group". Main reasons for each patient in PG were showed in supplement 2. The ICU LOS was $66.63 \pm 13.48 \mathrm{~h}$ in $\mathrm{PG}$ and $35.21 \pm 8.19 \mathrm{~h}$ in $\mathrm{nPG}$, $P<0.001$. The flow chart of patients' enrollment was showed in Fig. 1.

\section{Baseline characteristics}

We analyzed the basic characteristics (age, gender, APACHEII and SOFA on 1st day) between the two group, and no significant differences were observed. We calculated the number of patients who have different comorbidities (CAD: coronary artery disease; COPD: chronic obstructive pulmonary disease; CKD: chronic kidney disease; HTN: hypertension; PMI: pacemaker implantation) and no differences were found between the 2 groups. More details were displayed in the Table 1 .

\section{Surgical and therapeutic information}

The surgical length of PG and nPG was $208.78 \pm 63.58$ min and $197.72 \pm 54.33 \mathrm{~min}$, respectively, with $P$ value being 0.100 . For prolonged and non-prolonged patients, amount of intraoperative fluid infusion was $1687.86 \pm$ $465.75 \mathrm{ml}$ and $1575.00 \pm 419.97 \mathrm{ml}(P=0.295)$ while amount of fluid input in the first $24 \mathrm{~h}$ in ICU was $2357.90 \pm 409.88 \mathrm{ml}$ and $2115.01 \pm 238.77 \mathrm{ml}(P=0.006)$, respectively. Considering types of surgery could influence postoperative perfusion, we collected data of surgical types (abdomen, chest, lung, esophagus, gynecology, great artery, others). None of them were significantly different between two groups. Vasoactive agent is another factor influencing peripheral prefusion. The number of patients with application of vasoactive drugs in the 1st $12 \mathrm{~h}$ in ICU were 7 out of 65 in PG and 15 out of 103 in nPG $(P=0.478)$. More details were displayed in the Table 2.

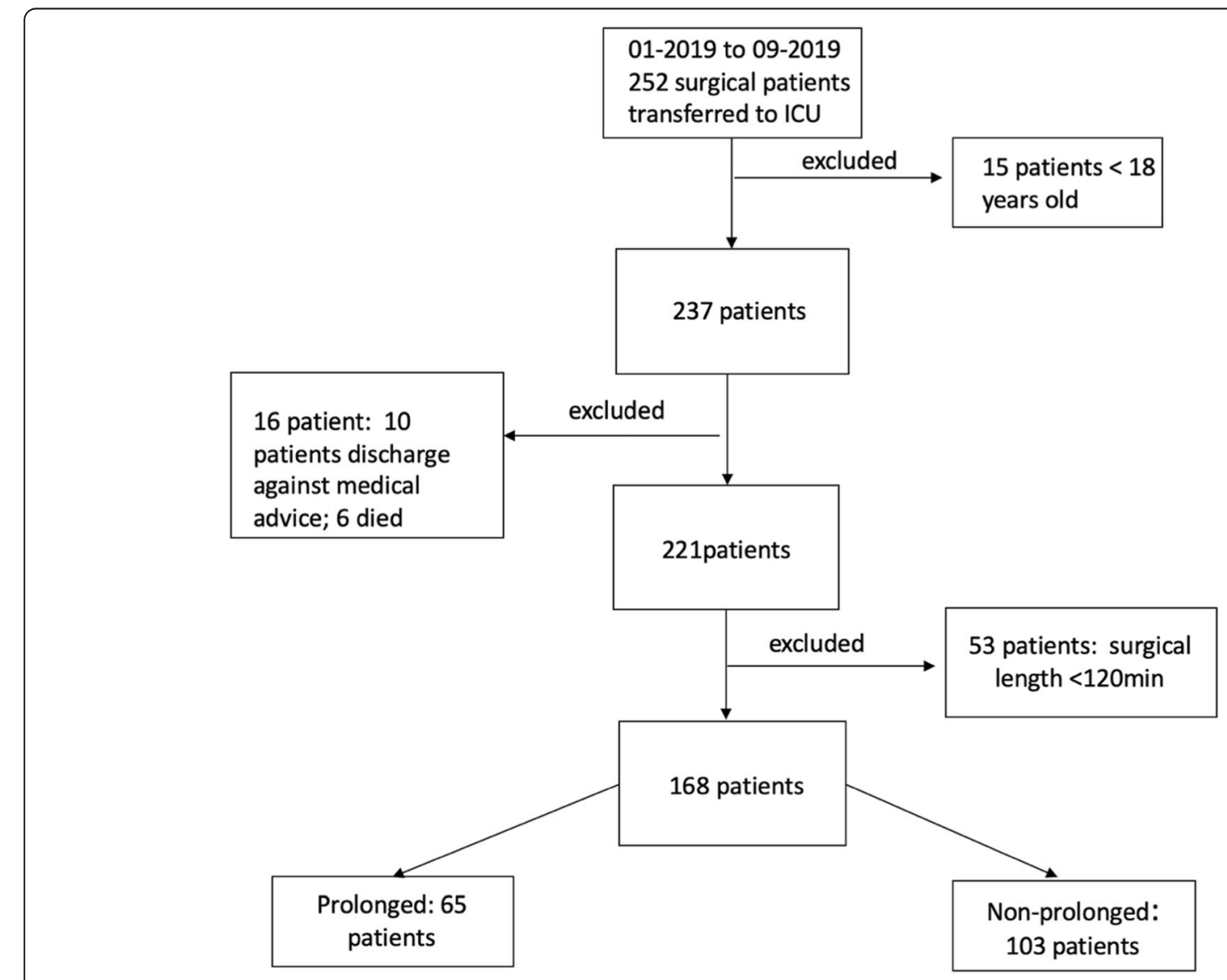

Fig. 1 Diagram showing the enrollment of patients 
Table 1 The baseline characteristics of enrolled patients

\begin{tabular}{|c|c|c|c|c|}
\hline & & $\begin{array}{l}\text { Prolonged ICU stay } \\
N=65\end{array}$ & $\begin{array}{l}\text { Non-prolonged ICU stay } \\
N=103\end{array}$ & $P$ \\
\hline \multicolumn{2}{|l|}{ Age /year } & $54.96 \pm 11.22$ & $57.37 \pm 10.51$ & 0.245 \\
\hline \multicolumn{2}{|l|}{ Gender male/\% } & $50 / 76.92 \%$ & $68 / 66.02 \%$ & 0.132 \\
\hline \multicolumn{2}{|l|}{ LOS ICU /h } & $66.63 \pm 13.48$ & $35.21 \pm 8.19$ & $<0.001$ \\
\hline \multicolumn{2}{|l|}{ APACHE ॥ } & $12.32 \pm 1.48$ & $12.09 \pm 1.66$ & 0.276 \\
\hline \multicolumn{2}{|l|}{ SOFA } & $5.09 \pm 1.43$ & $4.97 \pm 1.36$ & 0.661 \\
\hline \multirow[t]{7}{*}{ Comorbidity } & $C A D$ & 16 & 22 & 0.763 \\
\hline & COPD & 10 & 9 & 0.282 \\
\hline & CKD & 7 & 6 & 0.383 \\
\hline & HTN & 20 & 29 & 0.850 \\
\hline & Diabetes & 10 & 16 & 1.000 \\
\hline & PMl & 7 & 8 & 0.699 \\
\hline & Others & 3 & 2 & 0.329 \\
\hline
\end{tabular}

LOS ICU length of ICU stay, APACHE I/ Acute Physiology and Chronic Health Evaluation, SOFA Sequential Organ Failure Assessment, CAD coronary artery disease, COPD chronic obstructive pulmonary disease, CKD chronic kidney disease, HTN hypertension, Others: atrial fibrillation, stroke, asthma

\section{Hemodynamic and perfusion indicators}

At three time points $\left(\mathrm{T}_{0}, \mathrm{~T}_{1}, \mathrm{~T}_{2}\right)$, we did not see any differences on HR, MAP and body temperate between the 2 groups. When patients arrived in ICU, there were no differences on the immediate $\left(\mathrm{T}_{0}\right)$ lactate between $\mathrm{PG}(3.08 \pm 0.72 \mathrm{mmol} / \mathrm{L})$ and $\mathrm{nPG}(3.09 \pm 0.73 \mathrm{mmol} / \mathrm{L})$. But after $\operatorname{six}\left(\mathrm{T}_{1}\right)$ and twelve hours $\left(\mathrm{T}_{1}\right)$, lactate in prolong group was higher than no-prolong group(T1: PG/nPG, $3.13 \pm 0.67 / 2.62 \pm 0.59 \mathrm{mmol} / \mathrm{L}, P=0.009 ; \mathrm{T} 2: \mathrm{PG} / \mathrm{nPG}$, $3.25 \pm 0.44 / 2.02 \pm 0.42 \mathrm{mmol} / \mathrm{L}, P<0.001)$.

Compared to lactate, PPI showed earlier indication: the value was lower in PG than $\mathrm{nPG}$ at $\mathrm{T}_{0}(1.09 \pm 0.33$ vs $1.41 \pm 0.45, P=0.001)$ as well as $\mathrm{T}_{1}(1.08 \pm 0.37$ vs $1.49 \pm 0.41, P<0.001)$. But the difference disappeared after $\quad 12 \mathrm{~h} \quad\left(\mathrm{~T}_{2}, \quad\right.$ PG/nPG: $1.17 \pm 0.27 / 1.23 \pm 0.33$, $P=0.392)$. More information was presented in Table 3 .

\section{Univariate and multivariable analysis}

Univariate regression analysis was performed for all potential risk factors of prolonged ICU stay. Only two variables were found significantly related: PPI $\left(\mathrm{T}_{0}, \mathrm{~T}_{1}\right)$, lactate $\left(\mathrm{T}_{1}, \mathrm{~T}_{2}\right)$. More details showed in Table 4 . Because $\mathrm{T}_{1}$ was the only time point at which both PPI and lactate were significantly associated with prolonged ICU stay, we performed the multivariable logistic regression using $\mathrm{PPI}_{\mathrm{T} 1}$ and lactate ${ }_{\mathrm{T} 1}$.

The multivariable logistic regression analysis demonstrated that lactate T1 $_{1}(\mathrm{OR} \quad 3.216 ; 95 \%$ CI $1.253-$ 8.254, $P=0.015)$ and $\mathrm{PPI}_{\mathrm{T} 1} \quad(\mathrm{OR} 0.070 ; 95 \% \quad \mathrm{CI}$ 0.016-0.307, $P<0.001)$ were independent predictors of prolonged ICU stay in surgical patients. In Table 5, more details of the logistic regression model were showed.

Table 2 Surgical and therapeutic information

\begin{tabular}{|c|c|c|c|c|}
\hline & & $\begin{array}{l}\text { Prolonged ICU stay } \\
N=65\end{array}$ & $\begin{array}{l}\text { Non-prolonged ICU stay } \\
N=103\end{array}$ & $P$ \\
\hline \multicolumn{2}{|l|}{ Surgical length /min } & $218.63 \pm 60.35$ & $195.83 \pm 54.84$ & 0.100 \\
\hline \multicolumn{2}{|c|}{ Intraoperative fluid infusion /ml } & $1687.86 \pm 465.75$ & $1575.00 \pm 419.97$ & 0.295 \\
\hline \multirow[t]{2}{*}{ Fluid balance $/ \mathrm{mL}$} & $0-6 h$ & $296.00 \pm 151.88$ & $280.24 \pm 110.44$ & 0.611 \\
\hline & $0-12 \mathrm{~h}$ & $395.67 \pm 174.29$ & $454.29 \pm 184.70$ & 0.179 \\
\hline \multicolumn{2}{|c|}{ Vasoactive agent n(\%) } & $7(10.77 \%)$ & $15(14.56 \%)$ & 0.478 \\
\hline \multirow[t]{6}{*}{ Operative types } & Abdominal & 21 & 38 & 0.660 \\
\hline & Chest & 8 & 16 & 0.722 \\
\hline & Lung & 10 & 10 & 0.389 \\
\hline & Esophagus & 7 & 14 & 0.765 \\
\hline & $\mathrm{GO}$ & 10 & 12 & 0.643 \\
\hline & GA & 9 & 13 & 1.000 \\
\hline
\end{tabular}


Table 3 Comparison of hemodynamic and perfusion parameters between the two groups

\begin{tabular}{|c|c|c|c|c|c|c|}
\hline & & $\begin{array}{l}\text { Prolonged ICU stay } \\
N=65\end{array}$ & $\mathrm{n} 1$ & $\begin{array}{l}\text { Non-prolonged ICU stay } \\
N=103\end{array}$ & $\mathrm{n} 2$ & $P$ \\
\hline \multirow[t]{3}{*}{ HR bpm } & $\mathrm{T}_{0}$ & $88.90 \pm 9.52$ & 65 & $89.45 \pm 10.39$ & 103 & 0.819 \\
\hline & $\mathrm{T}_{1}$ & $82.87 \pm 5.88$ & 65 & $83.50 \pm 5.45$ & 103 & 0.640 \\
\hline & $\mathrm{T}_{2}$ & $80.40 \pm 7.44$ & 65 & $80.81 \pm 6.51$ & 103 & 0.805 \\
\hline \multirow[t]{3}{*}{$\mathrm{MAP} / \mathrm{mmHg}$} & $\mathrm{T}_{0}$ & $74.52 \pm 6.83$ & 65 & $76.28 \pm 8.33$ & 103 & 0.221 \\
\hline & $\mathrm{T}_{1}$ & $75.33 \pm 4.86$ & 65 & $75.49 \pm 5.21$ & 103 & 0.864 \\
\hline & $\mathrm{T}_{2}$ & $74.74 \pm 5.49$ & 65 & $74.58 \pm 5.62$ & 103 & 0.883 \\
\hline \multirow[t]{3}{*}{ Lactate mmol/L } & $\mathrm{T}_{0}$ & $3.08 \pm 0.72$ & 65 & $3.09 \pm 0.73$ & 103 & 0.978 \\
\hline & $\mathrm{T}_{1}$ & $3.13 \pm 0.67$ & 58 & $2.72 \pm 0.59$ & 89 & 0.009 \\
\hline & $\mathrm{T}_{2}$ & $3.15 \pm 0.44$ & 61 & $2.02 \pm 0.42$ & 92 & 0.001 \\
\hline \multirow[t]{3}{*}{ PPI } & $\mathrm{T}_{0}$ & $1.09 \pm 0.33$ & 65 & $1.41 \pm 0.45$ & 103 & 0.001 \\
\hline & $\mathrm{T}_{1}$ & $1.08 \pm 0.37$ & 65 & $1.49 \pm 0.41$ & 103 & $<0.001$ \\
\hline & $\mathrm{T}_{2}$ & $1.17 \pm 0.27$ & 65 & $1.23 \pm 0.33$ & 103 & 0.392 \\
\hline \multirow[t]{3}{*}{$\mathrm{T} /{ }^{\circ} \mathrm{C}$} & $\mathrm{T}_{0}$ & $36.45 \pm 0.33$ & 65 & $36.46 \pm 0.35$ & 103 & 0.875 \\
\hline & $\mathrm{T}_{1}$ & $36.84 \pm 0.20$ & 65 & $36.81 \pm 0.21$ & 103 & 0.422 \\
\hline & $\mathrm{T}_{2}$ & $37.02 \pm 0.42$ & 65 & $36.98 \pm 0.41$ & 103 & 0.626 \\
\hline
\end{tabular}

$H R$ heart rate, MAP mean artery pressure, $P P I$ peripheral perfusion index, $T$ temperature

\section{ROC analyses}

ROC curves were drawn to compare the predictive values of $\mathrm{PPI}_{\mathrm{T} 1}$, lactate ${ }_{\mathrm{T} 1}$ for prolonged ICU stay (Fig. 2). The AUC (area under curve) demonstrated that the predictive values of $\mathrm{PPI}_{\mathrm{T} 1}$ and lactate $\mathrm{T}_{1}$ were $0.772(95 \% \mathrm{CI}$ : $0.658-0.886$ ) and 0.677 (95\% CI, 0.550-0.803) (Table 6). The cutoff values for $\mathrm{PPI}_{\mathrm{T} 1}$ and lactate $\mathrm{T}_{1}$ were 1.35 (sensitivity: $83.3 \%$; specificity: $73.8 \%$ ) and 3.10 (sensitivity: 50\%; specificity: $78.6 \%)$ respectively, based on the maximum Youden index.

\section{Discussion}

The most important finding of this research is association between PPI and length of ICU stay. If PPI can reach 1.35 within the first $6 \mathrm{~h}$ in ICU, it gives physicians a hint that this patient could discharge from ICU within $48 \mathrm{~h}$, with $83.3 \%$ sensitivity and $73.8 \%$ specificity. Besides, we also proved that PPI indicated prolonged ICU stay more superior and earlier than lactate.

\section{Why PPI can predict prolonged ICU stay and is superior to lactate}

Peripheral perfusion index (PPI) is an indicator mirrorring inadequate perfusion in critical patients [7]. It is measured using pulse co-oximetry technology which is characterized by being real-time and noninvasive. PPI is defined as "the ratio of pulsatile blood flow to the non-pulsatile blood flow", mirroring the strength of blood flow and quality of perfusion at sensor site, reflecting perfusion state of the body part $[9,10]$. Compared to blood lactate testing, PPI is real-time and non-invasive [9].
Many researches have proved quality of perfusion is essential for critical patients in the process of recovery $[2,8,11,12]$. Poor perfusion prolongs patients' inhospital stay and increases mortality and morbidity [11]. That is why PPI, a regional perfusion indicator, is related to length of ICU stay. Lower PPI means poorer perfusion and longer ICU stay. But there is another question: why PPI is superior to lactate, an index that has been widely validated and used. Before we figure it out, we need to know alterations of blood flow during hypoperfusion.

At the initial stage of hypoperfusion, peripheral vessels contract in order to return enough blood to heart [13, 14]. In this phase, macro vital signs, like $H R$ and $B P$, are normal. Because macro circulation is stable, blood lactate does not increase. But PPI, an indicator of regional perfusion, will decrease because vascular contraction reduces reginal blood flow. This makes PPI superior to other macro parameters, for example lactate, in alerting physicians to hypoperfusion.

We can see this superiority of PPI from our results. At $\mathrm{T}_{0}$, PPI showed significant differences between PG and nPG, but lactate was not statistically different. After $6 \mathrm{~h}$, lactate became significantly different between PG and nPG at $T_{1}$. There was a delay in lactate comparing to PPI. In order to find out more details about tendency of lactate in two groups, we performed Wilcoxon signedrank test (abnormal distribution) and found out that lactate showed no obvious decreasing trend in prolonged group while dramatically reduced in non-prolonged group (see supplement3). PPI was higher in $\mathrm{nPG}$ than PG both at $T_{0}$ and $T_{1}$. Considering that PPI has been 
Table 4 Univariate logistic regression analysis for possible risk factors of prolonged ICU stay

\begin{tabular}{|c|c|c|c|c|c|c|c|c|}
\hline \multirow[t]{2}{*}{ Variable } & \multirow[t]{2}{*}{ B } & \multirow[t]{2}{*}{ SE } & \multirow[t]{2}{*}{ Wald } & \multirow[t]{2}{*}{$P$} & \multirow[t]{2}{*}{ OR } & & \multicolumn{2}{|c|}{$95 \% \mathrm{Cl}$ for OR } \\
\hline & & & & & & & Lower & Upper \\
\hline \multicolumn{9}{|l|}{ Univariate } \\
\hline \multicolumn{2}{|l|}{ Age /y } & -0.028 & 0.025 & 1.212 & 0.271 & 0.973 & 0.926 & 1.022 \\
\hline \multicolumn{2}{|l|}{ Gender } & 0.455 & 0.355 & 1.641 & 0.200 & 1.576 & 0.786 & 3.162 \\
\hline \multicolumn{2}{|l|}{ SOFA } & 0.080 & 0.171 & 0.220 & 0.639 & 1.084 & 0.775 & 1.516 \\
\hline \multicolumn{2}{|l|}{ APACHE ॥ } & 0.153 & 0.184 & 0.692 & 0.406 & 1.166 & 0.812 & 1.672 \\
\hline \multicolumn{2}{|c|}{ Surgical length /ml } & 0.007 & 0.004 & 2.671 & 0.102 & 1.007 & 0.999 & 1.015 \\
\hline \multicolumn{2}{|c|}{ Intraoperative fluid infusion } & -0.001 & 0.001 & 1.113 & 0.291 & 0.999 & 0.998 & 1.000 \\
\hline \multirow[t]{2}{*}{ Fluid balance /ml } & $0-6 h$ & -0.001 & 0.002 & 0.265 & 0.606 & 1.001 & 0.997 & 1.005 \\
\hline & $0-12 \mathrm{~h}$ & -0.002 & 0.001 & 1.809 & 0.179 & 0.998 & 0.995 & 1.001 \\
\hline \multirow[t]{3}{*}{ HR bpm } & TO & -0.006 & 0.024 & 0.054 & 0.816 & 0.994 & 0.948 & 1.043 \\
\hline & $\mathrm{T} 1$ & -0.020 & 0.043 & 0.226 & 0.634 & 0.980 & 0.900 & 1.066 \\
\hline & $\mathrm{T} 2$ & -0.009 & 0.035 & 0.063 & 0.802 & 0.991 & 0.925 & 1.062 \\
\hline \multirow[t]{3}{*}{$\mathrm{MAP} / \mathrm{mmHg}$} & TO & -0.013 & 0.033 & 0.165 & 0.685 & 0.987 & 0.926 & 1.052 \\
\hline & $\mathrm{T} 1$ & -0.021 & 0.049 & 0.180 & 0.671 & 0.979 & 0.890 & 1.078 \\
\hline & $\mathrm{T} 2$ & 0.034 & 0.042 & 0.651 & 0.420 & 1.034 & 0.953 & 1.123 \\
\hline \multirow[t]{3}{*}{ PPI } & TO & -2.088 & 0.701 & 8.866 & 0.003 & 0.124 & 0.031 & 0.490 \\
\hline & $\mathrm{T} 1$ & -2.586 & 0.734 & 12.424 & $<0.001$ & 0.075 & 0.018 & 0.317 \\
\hline & $\mathrm{T} 2$ & -1.296 & 0.850 & 2.327 & 0.127 & 0.274 & 0.052 & 1.447 \\
\hline \multirow[t]{3}{*}{ Lactate /mmol. L } & TO & -0.009 & 0.334 & 0.001 & 0.978 & 0.991 & 0.515 & 1.907 \\
\hline & $\mathrm{T} 1$ & 1.023 & 0.407 & 6.331 & 0.012 & 2.783 & 1.254 & 6.175 \\
\hline & $\mathrm{T} 2$ & 4.645 & 1.000 & 21.575 & $<0.001$ & 104.103 & 14.662 & 739.179 \\
\hline \multirow[t]{3}{*}{$\mathrm{T} /{ }^{\circ} \mathrm{C}$} & TO & -0.039 & 0.718 & 0.003 & 0.957 & 0.962 & 0.236 & 3.929 \\
\hline & $\mathrm{T} 1$ & 1.689 & 1.221 & 1.912 & 0.167 & 5.412 & 0.494 & 59.257 \\
\hline & $\mathrm{T} 2$ & 0.365 & 0.574 & 0.405 & 0.524 & 1.441 & 0.468 & 4.441 \\
\hline
\end{tabular}

proved effective in reflecting perfusion state, the different tendencies in two groups probably result from PPI. From the.

In order to confirm lactate is not real-time enough to predict poor prognosis, we performed a similar multivariable logistic regression (see supplement 4). In that model, lactate $\mathrm{T}_{0}$ is not associated with prolonged ICU stay while $\mathrm{PPI}_{\mathrm{T} 0}$ is relevant with it. We also plotted ROC curves of $\mathrm{PPI}_{\mathrm{T} 1}$ and lactate $\mathrm{T}_{\mathrm{T} 1}$ for predicting prolonged ICU stay. The AUC of $\mathrm{PPI}_{\mathrm{T} 1}$ and lacatate $\mathrm{T}_{1}$ are 0.772 and 0.677 respectively. These results showed us that PPI predict prolonged ICU stay earlier and better.

Table 5 Multivariate logistic regression analysis for possible risk factors of prolonged ICU stay

\begin{tabular}{|c|c|c|c|c|c|c|c|}
\hline \multirow[t]{2}{*}{ Variable } & \multirow[t]{2}{*}{ B } & \multirow[t]{2}{*}{ SE } & \multirow[t]{2}{*}{ Wald } & \multirow[t]{2}{*}{$P$} & \multirow[t]{2}{*}{ OR } & \multicolumn{2}{|c|}{$95 \% \mathrm{Cl}$ for OR } \\
\hline & & & & & & Lower & Upper \\
\hline $\mathrm{PPI}_{\mathrm{T} 1}$ & -2.666 & 0.758 & 12.379 & $<0.001$ & 0.070 & 0.016 & 0.307 \\
\hline $\mathrm{Lac}_{\mathrm{T} 1}$ & 1.168 & 0.481 & 5.901 & 0.015 & 3.216 & 1.253 & 8.254 \\
\hline
\end{tabular}

\section{The role of PPI in managing postoperative patients'} treatment

Patients undergoing long time surgeries tend to manifest high level of blood lactate $[15,16]$. It is known to us all that hyperlactacidemia is a strong indicator for poor prognosis [12, 17]. If we want to reduce blood lactate, we need to ensure adequate perfusion. According to our conclusions, intensivists should pay more attention to PPI, an invasive and real-time indicator, which has been proved superior to lactate in predicting patients' prognosis. In a previous study [18], PPI $<1.4$ is a sign of hypoperfusion in critical patients. Our conclusion is that PPI $<1.35$ after $6 \mathrm{~h}$ in ICU predicts LOS ICU longer than $48 \mathrm{~h}$ with $83.3 \%$ sensitivity and $73.8 \%$ specificity, which is similar to Lima AP's study [18].

In clinic practice, intensivists should be aware of postsurgical patients' alterations of PPI. If PPI shows obvious trend of declination, doctors should be cautious of hypoperfusion and poor prognosis. They need to find out the 

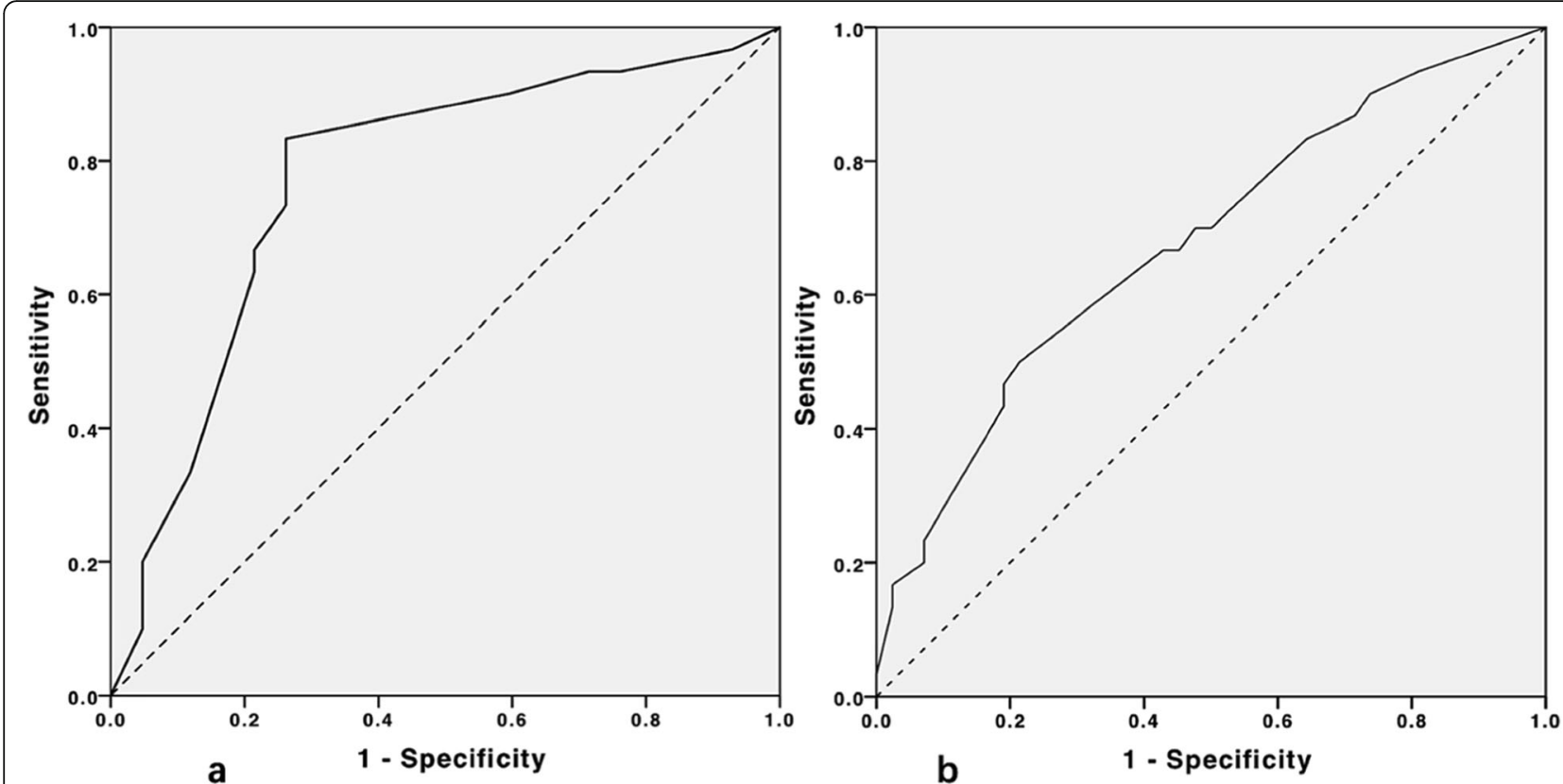

Fig. 2 The ROC curves of $\mathrm{PPI}_{\mathrm{T} 1}$ and lactate $\mathrm{T}_{1}$ for prolonged ICU stay in surgical patients transferred to ICU. a: The ROC curve of PPTT1 in predicting prolonged ICU stay. The dotted line is reference line; solid line is PPTT1; $\mathbf{b}$ : The ROC curve of lactateT1 in predicting prolonged ICU stay; The dotted line is reference line

reason of its decrease and rule out non-perfusion relevant factors, trying to restore adequate perfusion.

\section{Factors that influence PPI}

One of the reasons limiting the use of PPI is that it is easily influenced by other factors. Low temperature and vascular diseases are the two main confounding factors which could affect value of PPI [18]. Besides, the position can also affect PPI [19]. If we place patients' arms on unsuitable positions, for example, placing arms under a weight, it will have negative effects on regional perfusion.

Before we apply PPI into clinic practice, we need to keep in mind that lower value does not mean poor perfusion unless we rule out other confounding factors. In this study, we excluded all patients with diseases affecting regional blood flow. In our routine nursing, we give warm-keeping service to all the patients, for example covering blankets. If necessary, we provide warm blower

Table 6 The results of ROC analysis of lactate $T_{1}$ and PPI $T_{1}$ predicting prolonged ICU stay

\begin{tabular}{llllll}
\hline Variables & ROC area & $95 \% \mathrm{Cl}$ & Cutoff value & Sensitivity & Specificity \\
\hline PPI T $_{1}$ & 0.772 & $0.658-0.886$ & $1.35^{\mathrm{C}}$ & $83.3 \%$ & $73.8 \%$ \\
Lac T $_{1}$ & 0.677 & $0.550-0.803$ & $3.10^{\text {d }}$ & $50.0 \%$ & $78.6 \%$
\end{tabular}

${ }^{\mathrm{a} P \mathrm{PI}} \mathrm{T}_{\mathrm{T}}<1.35$, predicting prolonged ICU stay with $83.3 \%$ sensitivity and $73.8 \%$ specificity

${ }^{\text {b }}$ Lactate $_{\mathrm{T} 1}>3.10 \mathrm{mmol} / \mathrm{L}$, predicting prolonged ICU stay with $50.0 \%$ sensitivity and $78.6 \%$ specificity to maintain patients' body temperature. Usually, we do not place any weights on patients' arms and all patients are in supine positions unless they require special treatments, for example prone position for acute respiratory distress syndrome. All patients enrolled in our study were supine.

\section{What is new about PPI in our study compared to previous ones}

Many studies proved PPI's predictive role in hypoperfusion $[6,7,20]$ and its association with mechanically ventilated patients' mortality [8]. What is novel in our study is that we compared PPI with lactate, which has not been showed in previous study and defined another important aspect of PPI: association with length of ICU stay.

Before our study, there is an important research carried out by Van Genderen ME [20] about exploring the superiority of different peripheral perfusion indicators. In that study [20], the siginificance of parameters relecting the state of peripheral perfusion in predicting the occurrence of post-operative complications had been proved. But it did not compare these indicators with the most widely used parameters relefcting perfusion: blood lactate. If we want to popularize a new parameter, we must compare its property with the extensively used one. That is why we perform our study, and luckily, we proved PPI's strenghth over lactate. 
In addition to that study, there is another research, written by Su L etc. [8], about the role of PPI in predicting mortality of patients with mechanical ventilation. Unlike Su's research [8], mainly focusing on patients with respiratory failure requiring mechanical ventilation, our study is about applying PPI in postoperative management.

\section{Limitations}

This study has several limitations. First, its sample size is small. More studies on PPI with bigger sample size should be carried out in the future. Second, patients who died in ICU or discharged against medical advice were excluded. This would cause the patients included in our study less severe. As we can see from the results, most patients' PPI could reach to around 1.2 within 12 $\mathrm{h}$. Besides, the highest average blood lactate in both groups was less than $4.0 \mathrm{mmol} / \mathrm{L}$. These phenomena indicate patients enrolled in the study were not so serious. It is better to confine our conclusions to surgical patients who are not in life-threatening conditions. As for patients on the edge of death, predicting their LOS ICU is much more complicated. Third, our studying period is only $12 \mathrm{~h}$. The reason why we focus on a short time is that we want to foresee patients' outcomes in early clinic phase. It is worth to note that many complications could appear in the late stage, these complications may postpone the discharge. A previous study had confirmed PPI alteration was associated with development of severe complications [20]. So, we have confidence that decreased PPI is associated with prolonged ICU stay even in the long term.

\section{Conclusions}

For surgical patients transferred to ICU, PPI and lactate at $\mathrm{T} 1(6 \mathrm{~h}$ after ICU admission) are associated with length of ICU stay. Compared to lactate, PPI reflects prolonged ICU stay earlier and better than lactate. The value of PPI at T1 lower than 1.35 has $83.3 \%$ sensitivity and $73.8 \%$ specificity in predicting LOS ICU longer than $48 \mathrm{~h}$.

\section{Supplementary information}

Supplementary information accompanies this paper at https://doi.org/10. 1186/s12871-020-01072-0.

Additional file 1.

Additional file 2.

Additional file 3.

\section{Abbreviations}

PPI: Peripheral perfusion index; SOFA: Sequential Organ Failure Assessment; APACHE II: Acute Physiology and Chronic Health Evaluation; HR: Heart rate; MAP: Mean artery pressure; ICU LOS: Length of ICU stay; T: Temperature;

Cl: Confidence interval; CC: Correlation coefficient; ROC: Receiver operating characteristic; AUC: Area under curve; CAD: Coronary artery disease; COPD: Chronic obstructive pulmonary disease; CKD: Chronic kidney disease; HTN: Hypertension; PMI: Pacemaker implantation; GO: Gynecological oncology; GA: Great artery

Acknowledgements

Not applicable.

Authors' contributions

$B L$ conceived and designed the study, interpreted data and helped draft the manuscript. XS participated in the study conception and design, recruited patients, collected data, performed the statistical analysis, interpreted the data and drafted the manuscript. MX and XY participated in technically support and data collection. All authors read and approved the final manuscript.

\section{Funding}

Not applicable.

\section{Availability of data and materials}

The datasets generated and/or analyzed during the current study are not publicly available due the security of our patients, but are available from the corresponding author on reasonable request.

\section{Ethics approval and consent to participate}

The Institutional Research and Ethics Committee of the Xinyang Central Hospital approved this study for human subjects. Because this retrospective study only collected clinical data, the Institutional Research and Ethics

Committee waived the need to obtain consent.

\section{Consent for publication}

Not applicable.

\section{Competing interests}

The authors declare that they have no competing interests.

Received: 6 March 2020 Accepted: 11 June 2020

Published online: 18 June 2020

\section{References}

1. Velickovic J, Palibrk I, Milicic B, Velickovic D, Jovanovic B, Rakic G, Petrovic M, Bumbasirevic $V$. The association of early postoperative lactate levels with morbidity after elective major abdominal surgery. Bosn J Basic Med Sci. 2019:19(1):72-80.

2. Lemke M, Karanicolas PJ, Habashi R, Behman R, Coburn NG, Hanna SS, Law $\mathrm{CHL}$, Hallet J. Elevated lactate is independently associated with adverse outcomes following hepatectomy. World J Surg. 2017;41(12):3180-8.

3. Kanazawa T, Egi M, Shimizu K, Toda Y, Iwasaki T, Morimatsu H. Intraoperative change of lactate level is associated with postoperative outcomes in pediatric cardiac surgery patients: retrospective observational study. BMC Anesthesiol. 2015;15:29.

4. Zhang Z, Xu X. Lactate clearance is a useful biomarker for the prediction of all-cause mortality in critically ill patients: a systematic review and metaanalysis*. Crit Care Med. 2014;42(9):2118-25.

5. Rhodes A, Evans LE, Alhazzani W, Levy MM, Antonelli M, Ferrer R, Kumar A, Sevransky JE, Sprung CL, Nunnally ME, et al. Surviving Sepsis campaign: international guidelines for Management of Sepsis and Septic Shock: 2016. Intensive Care Med. 2017;43(3):304-77.

6. He HW, Liu DW, Long Y, Wang XT. The peripheral perfusion index and transcutaneous oxygen challenge test are predictive of mortality in septic patients after resuscitation. Crit Care (London, England). 2013;17(3):R116.

7. Sivaprasath P, Mookka Gounder R, Mythili B. Prediction of shock by peripheral perfusion index. Indian J Pediatr. 2019;86(10):903-8.

8. Su L, Zhang R, Zhang Q, Xu Q, Zhou X, Cui N, Wang H, Wang X, Chai W, Rui $X$, et al. The effect of mechanical ventilation on peripheral perfusion index and its association with the prognosis of critically ill patients. Crit Care Med. 2019;47(5):685-90

9. van Genderen ME, van Bommel J, Lima A. Monitoring peripheral perfusion in critically ill patients at the bedside. Curr Opin Crit Care. 2012;18(3):273-9. 
10. Tafner P, Chen FK, Rabello RF, Correa TD, Chaves RCF, Serpa AN. Recent advances in bedside microcirculation assessment in critically ill patients. Rev Bras Ter Intensiva. 2017;29(2):238-47.

11. Houwink AP, Rijkenberg S, Bosman RJ, van der Voort PH. The association between lactate, mean arterial pressure, central venous oxygen saturation and peripheral temperature and mortality in severe sepsis: a retrospective cohort analysis. Crit Care (London, England). 2016;20:56.

12. Rishu AH, Khan R, Al-Dorzi HM, Tamim HM, Al-Qahtani S, Al-Ghamdi G, Arabi YM. Even mild hyperlactatemia is associated with increased mortality in critically ill patients. Crit Care (London, England). 2013;17(5):R197.

13. Vincent JL, Ince C, Bakker J. Clinical review: Circulatory shock--an update: a tribute to Professor Max Harry Weil. Crit Care (London, England). 2012;16(6):239

14. Vincent JL, De Backer D. Circulatory shock. N Engl J Med. 2013;369(18): 1726-34.

15. Maillet JM, Le Besnerais $P$, Cantoni M, Nataf $P$, Ruffenach A, Lessana A, Brodaty D. Frequency, risk factors, and outcome of hyperlactatemia after cardiac surgery. Chest. 2003;123(5):1361-6.

16. Demers $\mathrm{P}$, Elkouri $\mathrm{S}$, Martineau R, Couturier A, Cartier R. Outcome with high blood lactate levels during cardiopulmonary bypass in adult cardiac operation. Ann Thorac Surg. 2000;70(6):2082-6.

17. Haas SA, Lange T, Saugel B, Petzoldt M, Fuhrmann V, Metschke M, Kluge S. Severe hyperlactatemia, lactate clearance and mortality in unselected critically ill patients. Intensive Care Med. 2016;42(2):202-10.

18. Lima AP, Beelen P, Bakker J. Use of a peripheral perfusion index derived from the pulse oximetry signal as a noninvasive indicator of perfusion. Crit Care Med. 2002;30(6):1210-3.

19. Tapar H, Karaman S, Dogru S, Karaman T, Sahin A, Tapar GG, Altiparmak F, Suren $M$. The effect of patient positions on perfusion index. BMC Anesthesiol. 2018;18(1):111.

20. van Genderen ME, Paauwe J, de Jonge J, van der Valk RJ, Lima A, Bakker J, van Bommel J. Clinical assessment of peripheral perfusion to predict postoperative complications after major abdominal surgery early: a prospective observational study in adults. Crit Care (London, England). 2014 18(3):R114.

\section{Publisher's Note}

Springer Nature remains neutral with regard to jurisdictional claims in published maps and institutional affiliations.

Ready to submit your research? Choose BMC and benefit from:

- fast, convenient online submission

- thorough peer review by experienced researchers in your field

- rapid publication on acceptance

- support for research data, including large and complex data types

- gold Open Access which fosters wider collaboration and increased citations

- maximum visibility for your research: over $100 \mathrm{M}$ website views per year

At $\mathrm{BMC}$, research is always in progress.

Learn more biomedcentral.com/submissions 